NRRI 96-07

\title{
POST-REFORM CONTINUATION OF SOCIAL GOALS
}

\author{
Robert J. Graniere, Ph.D. \\ Senior Institute Economist \\ THE NATIONAL REGULATORY RESEARCH INSTITUTE \\ The Ohio State University \\ 1080 Carmack Road \\ Columbus, Ohio 43210-1002 \\ (614) $292-9404$
}

January 1996

This report was prepared by The National Regulatory Research Institute (NRRI) with funding provided by participating member commissions of the National Association of Regulatory Utility Commissioners (NARUC). The views and opinions of the author do not necessarily state or reflect the views, opinions, or policies of the $\mathrm{NRRI}$, the NARUC, or NARUC member commissions.

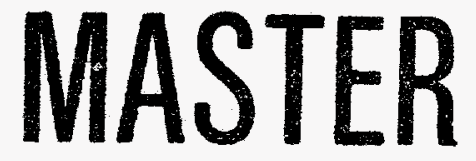




\section{DISCLAIMER}

This report was prepared as an account of work sponsored by an agency of the United States Government. Neither the United States Government nor any agency thereof, nor any of their employees, make any warranty, express or implied, or assumes any legal liability or responsibility for the accuracy, completeness, or usefulness of any information, apparatus, product, or process disclosed, or represents that its use would not infringe privately owned rights. Reference herein to any specific commercial product, process, or service by trade name, trademark, manufacturer, or otherwise does not necessarily constitute or imply its endorsement, recommendation, or favoring by the United States Government or any agency thereof. The views and opinions of authors expressed herein do not necessar. ily state or reflect those of the United States Government or any agency thereof. 


\section{DISCLAMIFR}

Portions of this document may be illegible in electronic inage products. Images are produced from the best available original document. 


\section{EXECUTIVE SUMMARY}

Six mechanisms, which are introduced in this paper, may be used to maintain social goals after the removal of barriers that clog entry into the generation market. However, these mechanisms are not perfect. The first mechanism, which uses general tax revenues to continue the support of social goals, creates tax increases. The second mechanism, which is a lump-sum fee assessed against all generation companies, has the potential to cause some unregulated companies to exit the generation market prematurely. The third mechanism, which extends the lump-sum fee to include transmission and distribution companies, is difficult to implement uniformly because these three types of companies are very different in a postreform environment. The fourth mechanism, which is an exit fee, is a penalty that retards economic growth and induces cut-backs in electricity consumption. The fifth mechanism, which places usage-based surcharges on unbundled regulated services, crumbles when these surcharges invite the production of substitutes for these regulated services. The sixth mechanism, which dedicates a line item in the traditional demand charge to the maintenance of social goals, may reduce the utility's profitability if customers subject to the charge have elastic demands and if providing for the continuation of social goals increases the prices of electric power for these customers.

Still, regulatory authorities can pursue two imperfect courses of action that have the potential to continue the maintenance of social goals. They can institute a Social Goals Support Fund that receives its monies through by lump-sum fees assessed against the regulated transmission and distribution companies. These fees do not alter the price and production levels of regulated services as long as the transmission and distribution companies are subject to unfettered price regulation. However, these desirable economic characteristics disappear when these companies are subject to profit regulation. In this instances, the fees are treated as extraneous costs of production that are rolled into the regulated company's revenue 
requirement with the result that regulated prices are increased and the production levels of regulated services are decreased.

Although lump-sum fees can be used to maintain social goals regardless of the regulatory format applied to transmission and distribution companies, they provide for the full maintenance of social goals only if they capture a sufficient amount of the supernormal profits that the utility earns in the transmission and distribution markets. ${ }^{1}$ Fortunately, the utility is in the position to earn supernormal profits in these markets because they are expected to be monopolies for some time after the removal of barriers to entry into the generation market. However, to implement the Social Goals Support Fund, the regulatory authorities have to be prepared to let the utility-owned transmission company and the utility-owned distribution companies exploit their market power over their customers. ${ }^{2}$

Another imperfect course of action available to the regulatory authorities is to set supracompensatory prices for unbundled transmission and distribution services. $^{3}$ These prices can be determined by adding surcharges to the efficient

1 A normal rate of return is the rate of return that a profit-maximizing, unregulated company earns in a competitive market. A supernormal rate of return is the rate of return that a profitmaximizing, unregulated company earns in a noncompetitive market.

2 The transmission company's customers are utility-owned generation companies, nonutility generators, rural cooperatives, municipally owned utilities, and utility-owned local distribution companies. The customers of the utility-owned local distribution companies are the residential, commercial, and industrial customers that pay retail rates for electricity services.

3 A subsidy-free price for a service offered by a multi-product company is defined as a price with the characteristic that the incremental revenue obtained by selling the given quantity of the service equals or exceeds the incremental cost that is incurred by producing that given quantity of the service. Sometimes, the sum of the incremental revenues received from the sale of a set of services at subsidy-free prices does not equal the total cost of producing that set of services. When this situation arises the company must realign its prices if it is to remain in business. See: William J. Baumol and J. Gregory Sidak, Toward Competition in Local Telephony, AEl Studies in Telecommunications Deregulation, (Cambridge, MA: the MIT Press and Washington, D.C.: The American Enterprise Institute for Public Policy Research, 1994). The realigned prices are compensatory prices when they are subsidy-free prices, and the company earns total revenues that do not exceed the company's total cost of production. The total cost of production includes the normal rate of return on investments. See: Gerald Faulhaber, "Cross-Subsidization: Pricing in Public Enterprise," American Economic Review 65 (1975): 966. A set of supracompensatory prices is defined as prices that are subsidy free, and the company earns a supernormal rate of return on investments. 
component prices of the unbundled transmission and distribution services that are sold to generation companies, local distribution companies, and retail customers. ${ }^{4}$ This procedure is an acceptable way to achieve the full maintenance of social goals as long as the surcharges do not create supracompensatory prices for unbundled regulated services that exceed their upper limits. ${ }^{5}$ In addition, the regulatory authorities have to be comfortable with compensatory prices for bundled retail services that are less than the sum of the supracompensatory prices for the unbundled transmission and distribution services and the competitive price for the unbundled generation service that make up a comparable competitive electricity service for the utility's retail customers.

Social goals can be maintained partially when market forces prevent the utility from proposing supracompensatory prices for unbundled transmission and distribution services that would maintain fully social goals. Partial maintenance can be obtained efficiently through the incentive regulation of these services. Incentive regulation permits the utility to earn supranormal profits that can be diverted

4 Efficient component prices have two components. The first is the average incremental cost of the unbundled transmission or distribution service. This cost is determined for an unbundled transmission service by summing up the variable and service-specific fixed costs that the transmission company incurs to produce the specific quantity of the particular unbundled service in question, given the quantities that it is producing of the remaining unbundled transmission services, and then dividing this sum by the specific quantity of service that is produced by the company. See: William J. Baumol, John C. Panzar, and Robert D. Willig, Contestable Markets and the Theory of Industry Structure, revised edition, (San Diego, CA: Harcourt Brace Jovanovich, Publishers, 1988). The second component is the averaged opportunity cost that the utility incurs when the utility-owned transmission company sells the unbundled transmission service in question to competitors. See: Baumol and Sidak, Toward Competition, 1994.

5 The prices of unbundled regulated services have upper limits regardless of market structure. When the markets for unbundled services are natural monopolies, the upper limits are the highest supracompensatory prices that sustain the monopolies. When the markets are not natural monopolies, the upper limits are the lower of the highest supracompensatory prices that are consistent with not allowing self generation to become a viable economic alternative for largevolume customers or with not allowing nonutility-owned transmission and distribution companies to become economically viable firms. 
partially to the maintenance of social goals. ${ }^{6}$ However, regulatory authorities should hold off on profit diversion until after they are convinced that the utilityowned generation companies have aggressively cut their costs in an effort to become competitive with nonutility generators. This delay is necessary because the utility has the opportunity and motive to subsidize its generation services with the supranormal profits that are earned from the sale of its unbundled services. ${ }^{7}$

The most important conclusion of this report is that significant profit increases from the remaining regulated markets will have to accompany the introduction of competition into the generation market if an effort is going to be made to ensure the full maintenance of social goals such as environmental protection, low-income assistance, demand-side management, and economic development. ${ }^{8}$ The conventional wisdom is that the utility cannot expect to earn supranormal profits in the generation market. In fact, everyone seems to believe that the utility initially will encounter some difficulty in the generation market because its generation companies have to focus on reducing their generation costs to ensure their survival in the market. Consequently, only the regulated transmission and distribution markets are left to the utility as sources of the supranormal profits that are required to maintain social goals. Therefore, the regulatory authorities cannot reform the electricity industry in a way that prevents

6 In effect, incentive regulation of monopolistic markets is the twin of supracompensatory prices under the rate-of-return regulation of monopolistic services.

7 The utility's has the motive to subsidize its generation services when its generation companies exhibit a cost disadvantage vis-a-vis nonutility generators.

8 A desire on the part of regulatory authorities to bring the benefits of competition to the generation market is not considered to be a social goal in this analysis. The term, social goal, is restricted to include only those public-policy objectives that may be in conflict with the emergence of an economicaliy efficient market for electricity. Economic efficiency is achieved when the sum of producer and consumer surplus is maximized. Therefore, the pursuit of any objective that might reduce the realized sum of producer and consumer surplus is perceived as the pursuit of a social goal. Obviously, this definition puts social goals in a bad light from the perspective of economic efficiency. However, this outcome is unavoidable. Therefore, it should not be interpreted as a strike against the post-reform continuation of social goals. 
the utility from proposing supracompensatory prices for unbundled transmission and distribution services.

Obviously, the utility would be in an untenable position with respect to the maintenance of social goals, if competition existed in the markets for unbundled transmission and distribution services. But, these markets currently are not competitive. Consequently, it is not necessary for the regulatory authorities and the utility to abandon their efforts to maintain social goals. 



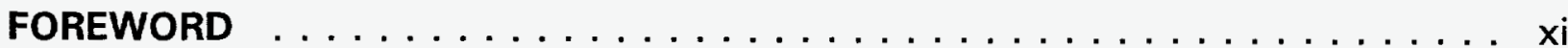

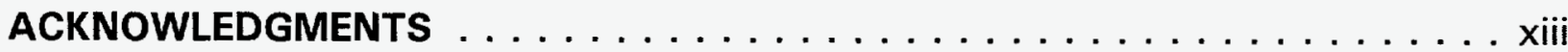

\section{SECTIONS}

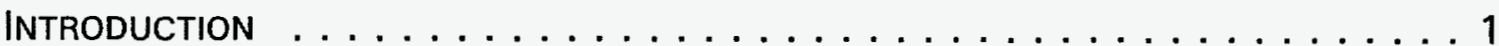

Post-Reform Cost Recovery and Pricing of Generation Services . . . . . . 5

Changing Focus to MaIntain Social Goals $\ldots \ldots \ldots \ldots \ldots$

USING UnBUNDLED TRANSMISSION AND DistribUtion SERVICES TO MAINTAIN SOCIAL GOALS . . . . . . . . . . . . . . . . . . . . 22

PRICE LIMITS ON UNBUNDLED TRANSMISSION AND

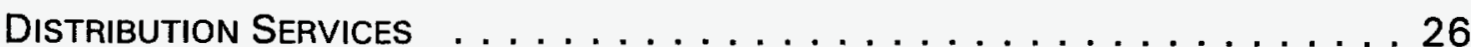

Six Mechanisms for the Maintenance of Social Goals $\ldots . . . \ldots . . . . .29$

Propping Up MaInTENANCE Mechanisms through

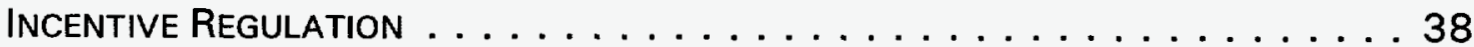

Ad Hoc Reform Elements Propping Up Maintenance Mechanisms $\ldots \ldots . . .41$

Regulatory Actions to Support the Maintenance of Social Goals $\ldots \ldots$

Concluding REMARKS $\ldots \ldots \ldots \ldots \ldots \ldots \ldots \ldots \ldots$ 


\section{FOREWORD}

Public utility regulators are currently wrestling with the issue of how and to what extent the social goals that have grown up around traditional regulation might be continued in a restructured electric power industry. This report critically examines six mechanisms that could be used for this purpose in the wake of the introduction of competition in the generation segment. Their pros and cons are thoroughly appraised in economic terms.

An important conclusion is that profitability in the regulated transmission and distribution markets will have to notably increase if the social goals are to be maintained at current levels and comprehensiveness by utilities.

Douglas N. Jones

Director, NRRI

Columbus, Ohio

January 1996 


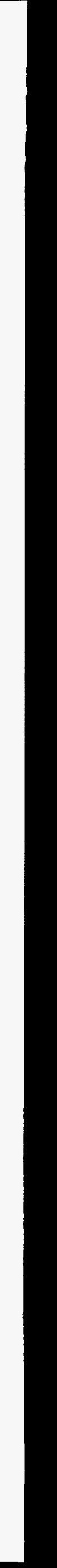




\section{ACKNOWLEDGMENTS}

I wish to express my thanks to Douglas Jones and Kenneth Costello for reviewing this report. Their comments helped me focus my efforts and clarify my exposition. However, I alone am responsible for any remaining errors.

I also would like to thank Francine Sevel for editing this report and Marilyn Reiss for typing the report. 


\section{INTRODUCTION}

The most talked about reform of the electric power industry is to increase the competitiveness of the generation market. This particular change in the structure of the electric power industry is receiving widespread attention because of falling natural gas prices, technological advances in the design and operation of natural gas turbines, new methods to explore for natural gas, and technological progress in the area of real-time information processing that can be used to manage the flow of electric power. ${ }^{1}$ A voluntary working group convened at the request of the California Public Utilities Commission reviewed many of the proposals to increase the competitiveness of the generation market. The working-group participants concluded that these proposals could be divided into four categories. ${ }^{2}$ Category I proposals use bilateral contracts to arrange for the purchase of competitive generation services. Category II proposals substantially alter the way transmission is provided in a post-reform electric power industry. Category III proposals stimulate the competitive interactions between buyers and sellers of generation services by removing entry barriers to generation market. Category IV proposals bring the benefits of competition to small-volume users more quickly than the other three types of reform proposals.

Bilateral contracts prescribe economic conduct between pairs of buyers and sellers of generation services. Ideally, these contracts represent commitments in the strongest sense of that term. That is, the contracts' terms and conditions

1 W. W. Hogan, "Reshaping the Electricity Industry," Mimeo, November 1994, Harvard University. W. W. Hogan and L. E. Ruff, "Reshaping the Electricity Industry: Competitive Market Structure and Regulatory Policy," Mimeo, November 1994.

2 California Advisory Staff, "Options for Commission Consideration," Mimeo, February 1995. 
define appropriate behavior that will be followed under any circumstances. However in reality, contracts often are breached when something better comes along. Consequently, reform proposals relying on bilateral contracts to organize the purchasing of competitive generation services have to be supplemented with customary practices and procedures available to buyers and sellers that act as backstops for breaches of contract. For example, sellers want practices and procedures that protect them from price fluctuations when buyers breach contracts because low-priced generation services are available on the spot market. Meanwhile, buyers want practices and procedures that enable them to replace generation services on a timely basis when sellers breach contracts because they have over committed their production facilities.

Proposals to substantially change the way transmission is provided are predicated on substantial changes in the structure of the transmission market and the structure of the company that provides transmission-access services to generation companies and transmission services to distribution companies. The pre-reform transmission market is part of a vertically integrated structure designed to easily connect regulated utilities to a transmission grid. The post-reform transmission market is a component of an industry structure designed to easily connect generation companies to their host transmission networks and distribution companies to the transmission grid. The pre-reform transmission company is responsible for bringing generation services owned by regulated utilities from generation sites to distribution sites. The post-reform transmission company is responsible for providing open and equal access to all generation companies and comparable transmission services to all distribution companies.

Often, it is proposed that the creation of a system operator, beyond the reach of the utility, is the way to ensure that the post-reform transmission company will fulfill its responsibilities. This independent system operator is not be subject to any incentives that would cause the post-reform transmission company to favor any generation or distribution company. Furthermore, it would not be required to 
ensure that electric power under its management is economically dispatched. Instead, the system operator only has to ensure that power under its control is dispatched consistently with the physics and dynamics of the transmission grid. Consequently, the primary objective of the post-reform system operator is to ensure the smooth, efficient, and seamless operation of the electric power industry by assuring the reliability, safety, and quality of the transmission grid.

The systematic removal of entry barriers to the generation market is the most basic reform proposal. The reform objective is to increase the competitiveness of the generation market by inducing the generation companies to become economically efficient producers of generation services. When confronted with efficient producers of generation services, it is believed that the post-reform distribution companies will become efficient resource portfolio managers for their service territories. In other words, they will have an opportunity to choose the combinations of competitively purchased generation services and demand-side management practices that minimize the life-cycle cost of reliable electricity to end users. Competitive procurement, targeted investments in demand-side management, a mix of short-term and long-term contracts for purchased power, spot-market purchases of electric power, and power pooling are the tools that the post-reform distribution companies will use to make the required choices.

Category IV reform proposals use energy marketeering to bring the benefits of competition more quickly to small-volume end users. Energy marketeering is a mixture of entrepreneurial activities that provides value to consumers. One type of marketer often helps its clients choose between different energy sources and then arranges for the delivery of the energy to its clients. This type is successful when it is possible to profit from arbitraging the prices of the different energy sources. This type also is successful when its clients pay a premium for the marketer's assistance in the selection of the mix of energy sources that best fit their needs. Another type of marketer helps its clients reduce their costs by organizing them into groups with buyers' power. Buyers' power puts these groups in the position 
to negotiate with the utility for lower prices. Consequently, energy marketeering is an effort to make the post-reform electricity market more efficient for everyone and more friendly to small-volume end users.

These four types of industry reform are in their formative stages, and consequently, they have not dealt comprehensively with all the issues that can arise during a reform effort. ${ }^{3}$ A partial list of the issues contains reasonable and nondiscriminatory rates for retail services; reasonable and nondiscriminatory rates for transmission-access services sold to generation companies; reasonable and nondiscriminatory rates for transmission services sold to distribution companies; adequate environmental, public health, and safety protection; acceptable service quality and service reliability levels; cost-effective promotion of demand-side management, renewable resources, environmentally preferred technologies and energy efficiency appliances; assistance for low-income customers; optimal fuel diversity and economic development, and maintenance of the protected status of selected business enterprises. This list is formidable, and therefore, no attempt is made in this analysis to address all of them. Instead, the analysis has a single focal point, which is the consistency of the removal of entry barriers to the generation market with the post-reform maintenance of social goals such as environmental protection, demand-side management, low-income assistance, and economic development. ${ }^{4}$

3 The California Public Utilities Commission noted this shortcoming when it issued its interim decision on market reform.

4 Bilateral contracting, energy marketing, and the efficient management of transmission market by an independent system operator are not particularly conducive to the maintenance of social goals. Bilateral contracting represents a conscious decision to minimize costs. One type of energy marketeering is successful when the exploitation of buyers' power enables groups of consumers to obtain lower prices from utilities. The efficient management of the transmission market cannot occur without efficient prices for transmission and transmission-access services. Consequently, no one wants prices for transmission and transmission-access services that include allowances for the maintenance of social goals. 
The remainder of this report discusses various aspects of funding an allowance for social goals after the proposed reform of the generation sector of the electric power industry. The next section considers post-reform cost recovery and market-based pricing when the wholesale segment of the generation sector is competitive. The following two sections address the conflict between the utility's profitability and the utility's maintenance of social goals. The first of these sections reviews the factors affecting the post-reform profitability of utility-owned generation companies. The second of these sections examines whether regulated markets can be pressed into service as the sources of funds for the post-reform maintenance of social goals. The section after that analyzes price limits on bundled and unbundled regulated services, demonstrating that these limits adversely affect the utility's ability to maintain social goals after industry reform. The following section evaluates six cost-recovery mechanisms meant to secure the utility's postreform maintenance of social goals. The next two sections discuss ways to increase the utility's post-reform profitability to enable it to maintain social goals in a post-reform electric power industry. The next-to-last section examines regulatory actions that support the utility's efforts to maintain social goals. Concluding remarks are offered in the final section.

\section{POST-REFORM COST RECOVERY AND PRICING OF GENERATION SERVICES}

The removal of entry barriers to the generation market raises the possibility that less costly generation technologies will be introduced more rapidly into this market by nonutility generators. The realization of this possibility results in the increased availability of lower-cost generation services to wholesale and retail customers. It is reasonable to suppose that these customers will take advantage of these lower-cost services by substituting nonutility generation for utility generation. It also is reasonable to suppose that these substitutions will cause some portion of 
the utility's investments in generation to become economically nonviable because they are technologically obsolete. ${ }^{5}$

When industry reform puts the recovery of some of the utility's generation costs in jeopardy through no fault of the utility, the typical regulatory response is to implement pricing standards that determine the character of the post-reform generation services and the contributions of these services to the recovery of postreform generation costs. For example, the staff of the California Public Service Commission suggested seven standards as guidelines for these purposes. ${ }^{6}$ Table 1 summarizes the staff's suggestions.

First, the staff suggested that the buyers of regulated and nonregulated generation services are entitled to the continuation of adequate, safe, reliable, and reasonably priced retail service after the removal of entry barriers to the generation market. Essentially, this standard prevents the utility from overreacting to the threatened competition from nonutility generators by holding the utility to the status quo with respect to the service characteristics of retail services. Consequently, this standard implies that the utility cannot cavalierly declare an excessive level of stranded investment because such a declaration threatens the utility's capability to raise the funds that are required to provide safe and reliable retail services. This capability may be adversely affected because investors may not feel that the utility will be able to fully recover the embedded costs of its

5 The history of the telecommunications industry contains several episodes where the introduction of new technologies created havoc with the economic viability of the regulated utility's existing investments. The most well-known episode is the introduction of new technologies to the customer-premises equipment market. The features and functions of private branch exchanges hastened the economic obsolescence of existing CENTREX equipment, while the vast majority of AT\&T-produced rotary-dial telephone sets were made technologically obsolete after non-AT\&Tproduced telephone sets were commonplace in the market.

6 Division of Strategic Planning, "California's Electric Services Industry: Perspectives on the Past, Strategies for the Future," February 1993, California Public Utilities Commission, San Francisco, 45, n. 42. 
TABLE 1

California's Standards for the Recovery of Post-Reform Generation Costs

Name

Description

Consumer Rights

Infrastructure Costs

Administrative Costs

Anti-Ramsey Prices

Stranded Costs

Cost Shifting

Environmental Protection
All buyers are entitled to adequate, safe, reliable, and reasonably priced electricity.

All buyers are responsible for the recovery of new infrastructure costs.

All buyers are responsible for the recovery of additional administrative costs.

Buyers with the most inelastic demands are not targeted for the recovery of post-reform costs.

Buyers of regulated services are not responsible for the recovery of a disproportionate share of stranded costs.

Small-volume buyers of regulated services are not targeted for the recovery of stranded costs.

Buyers of nonregulated services are responsible for helping to enhance environmental quality.

Source: Author construct 
stranded investments. The utility's technical operations are threatened because the utility may have induced a too rapid replacement of its generation investment.

The second standard suggested by the staff is that the costs of the new transmission and distribution infrastructure, which the utility incurred to accommodate a more competitive generation market, should be fairly shared by the buyers of nonregulated generation services and regulated retail services. Although this standard is soft because it leaves open the question of what constitutes fair sharing between regulated and nonregulated services, it does allude to the possibility that buyers of regulated retail services will be responsible for a portion of the recovery of new transmission and distribution costs.

The staff's third standard is that the administrative costs incurred during the transition to a more competitive generation market should not damage the utility's financial integrity. ${ }^{7}$ This standard clearly implies that these costs should be recovered only up to the threshold level of profitability that constitutes financial integrity for the utility. However, the standard does not lay out what level of profitability implies financial integrity. Furthermore, the standard does not provide guidance with respect to the fair recovery of transition costs from the utility's generation, transmission, and distribution customers.

The staff's fourth through seventh standards shed some light on the fairness issue. The fourth standard states that the utility's less-mobile customers should not be responsible for the recovery of a disproportionate share of the costs incurred to create a more competitive generation market. This standard implies that Ramsey pricing or the inverse-elasticity rule are not viable pricing tools for the recovery of these costs. ${ }^{8}$ Consequently, there is some evidence that fairness involves the protection of buyers with the more inelastic market demands.

7 ibid., $7,10,28,29,47$

8 Frank P. Ramsey, "A Contribution to the Theory of Taxation," Economic Journal 37 (1927): 47. William J. Baumol and David F. Bradford, "Optimal Departures form Marginal Cost Pricing," American Economic Review 67 (1977): 350. 
Their fifth standard indicates that the buyers of regulated services should be held harmless when it comes to the recovery of stranded costs. This standard means that the total amount of post-reform revenues that regulated services contribute to the recovery of the sum of used and useful regulated investments and stranded investments is exactly equal to the total amount of pre-reform revenues that regulated services contributed to the recovery of used and useful regulated investments. Consequently, as an element of fairness, this standard establishes that the various classes of regulated customers should not shoulder a disproportionate burden with respect to the recovery of stranded costs. ${ }^{9}$

The staff's sixth standard is that post-reform costs, including the costs of stranded investments, should not be inequitably shifted to small-volume retail customers. This standard supplements the standards pertaining to the inapplicability of Ramsey pricing and the protection of various classes of postreform regulated customers. Consequently, it implies that fairness is associated with providing small-volume customers with special attention in the post-reform markets.

The staff's seventh standard requires the utility to make a credible promise that it will support resource diversity and environmental quality. A credible promise is a promise that is likely to be kept in the face of adversity. Because the reform of the generation market might threaten the utility's financial position in the generation market, this standard suggests that buyers of nonregulated generation services may have to contribute something in support of the maintenance of these social goals.

These seven standards affect the selection of the pricing approach that is used to recover post-reform generation costs. The staff of the California Public Utilities Commission suggested a three-stage procedure for making this selection. ${ }^{10}$

9 Division of Strategic Planning, "Perspectives on the Past, Strategies for the Future," 45.

10 lbid., 45, n. 42. 
The procedure begins with the fashioning of three market-based institutions. ${ }^{11}$ The first determines the market price of generation services; the second determines utility-specific levels of stranded generation costs; the third involves giving weights to the seven standards to reduce the risk of recovering post-reform generation costs. ${ }^{12}$ Obviously, standards are reconciled with each other during the third stage of the procedure. For example, consider a potential reconciliation of the costshifting and stranded costs standards.

Suppose that the reconciliation is to assign to the utility's regulated books only the minimum amount of generation assets that are needed to meet the consumer demand for bundled retail services. This cost-assignment procedure implies that inequitable cost shifting involves any situation where any portion of the responsibility for the recovery of stranded generation costs is assigned to the buyers of regulated retail services. Conversely, this procedure implies that the buyers of nonregulated generation services are responsible for the complete recovery of stranded generation costs. However, the utility's investors face greater risks when stranded generation costs are assigned residually to nonregulated generation services because the costs of producing these services are increased. Consequently, the reconciliation of the minimum assignment of generation costs to the utility's regulated books works against the utility's efforts to successfully produce and sell nonregulated generation services. Hence, it has the ancillary effect of creating benefits for the utility's competitors. Therefore, this

\footnotetext{
${ }^{11}$ An institution is a structured decisionmaking process with a well-regarded history in the eyes of the public. For example, the practice of a democratic government is an example of a political institution. An example of a market-based institution is letting the competitive process decide how a product or service will be sold and delivered to the buyer. In effect, the competitive market is perceived as structured decision making with a well-regarded history.

${ }^{12}$ William J. Baumol, Paul L. Joskow, and Alfred E. Kahn, "The Challenge for Federal and State Regulators: Transition from Regulation to Efficient Competition in Electric Power, Appendix $A, "$ in [unknown] (n.p.), December 9, 1994.
} 
reconciliation pushes the reform of the generation market in the direction of minimizing the utility's ability to compete effectively in this market. ${ }^{13}$

However, in terms of public policy, it is surely not necessary that the entire responsibility for the recovery of stranded generation costs has to be placed on the utility's nonregulated generation services. It is possible and perhaps preferable to distribute this responsibility over the utility's regulated and nonregulated services. A reconciliation that achieves this policy objective is for the regulatory authorities to mandate that the stranded generation costs, allocated to regulated services, shall not be less on a per-unit basis than the stranded generation costs that were allocated to the utility's nonregulated generation services. This cost-allocation procedure implies that the buyers of regulated services equally share in the recovery of stranded generation costs with the buyers of nonregulated generation services.

The treatment of post-reform generation costs, especially stranded generation costs, is an important part of any effort to systematically remove entry barriers to the generation market. Even if the Averch-Johnson effect is not relevant with respect to the utility's total costs because the actual ratio of fixed to variable costs is efficient, ${ }^{14}$ the political realities of the utility's economic regulation induce cost allocations and cost assignments to regulated and nonregulated services that encourage the continuation of particular social programs and deter the continuation of others. Still, cost questions should not be allowed to dominate the analysis of an effort to reform the generation market. Considerable attention has to be paid to the institutional forces that affect the pricing of regulated and nonregulated services. A standard useful in this regard is that the prices of bundled regulated

\footnotetext{
${ }^{13}$ The minimum-assignment cost-allocation procedure also causes the utility's regulated retail customers to enjoy price reductions under traditional rate-of-return regulation because of the reduction in the level of fixed costs allocated to regulated services. Therefore, this procedure also maximizes the gains from competition realized by traditional retail customers.

14 Harvey Averch and Leland L. Johnson, "Behavior of the Firm under Regulatory Constraint," American Economic Review 52 (1962): 1053.
} 
services, which are sold to retail customers, should not increase for a prespecified period of time. In other words, the industry reform effort is coupled with a moratorium on rate increases for a specific class of regulated services.

The rate-moratorium standard has the trait of perfectly insulating the users of bundled regulated services from price increases and consumption decreases. Also, it does not harm the utility's competitors in the generation market because the utility cannot compensate itself for lowering the prices of its nonregulated generation services by increasing the prices of bundled regulated services. These two facts imply that the rate-moratorium standard is perfectly acceptable when the immediate effect of the reform of the generation market is to decrease the utility's total cost of producing regulated and nonregulated services. In this case, the utility's inability to raise the prices for the bundled regulated services does not have any bite because the utility can use its cost savings from either side of its business as the source of price reductions for nonregulated generation services.

Of course, a rate-moratorium standard, in the context of declining total costs after the reform of the generation market, is not acceptable to those policy makers that believe that the buyers of regulated services should benefit, in some fashion, from the reform effort in the generation market. These individuals would share the cost reductions realized in the generation market with regulated customers.

Moreover, they would argue that the fairness criteria are violated when the prices of regulated services are not reduced after cost savings arise in the generation market. Their support for this argument is that unbundled generation services are components of bundled retail services.

In addition, the adoption of a rate-moratorium standard is questionable when it is known that the reform of the generation market causes an increase in the utility's total costs. The prohibition against adjusting the prices of regulated services ensures that the utility's nonregulated generation services and unbundled regulated services are candidates for the recovery of all types of post-reform costs. The first option does not bode well for the utility and its stockholders because the 
utility's nonregulated generation services are offered to buyers with an alternative. This alternative, essentially the capability to purchase electric power services from nonutility generators, implies that the utility will find it difficult to impossible to maintain price increases for nonregulated services for any period of time. The only way for the utility to respond to this economic fact of life is to try and recover its post-reform total costs by raising the prices of unbundled-but-regulated transmission and distribution services. However, the competitiveness of the generation market can be adversely affected by inefficient increases in the prices of unbundled transmission-access services. ${ }^{15}$ Meanwhile, the retail buyers of nonregulated generation services can be adversely affected by price increases for unbundled distribution services because they rely on these services for the last mile of their service delivery configurations. ${ }^{16}$

Fortunately for the utility's customers and stockholders, the systematic removal of entry barriers to the generation market is not a random event. Usually, identifiable technological drivers have precipitated the efforts to reform the industry in this manner. One of these drivers is communications advances that reduce the costs of integrating the information used to manage and operate a transmission grid with the information used to set real-time prices for retail services. With respect to system operation and management, these information-processing innovations and inventions hold out the hope of enabling system operators to better coordinate the

15 William J. Baumol and J. Gregory Sidak, Toward Competition in Local Telephony, AEI Studies in Telecommunications Deregulation, (Cambridge, MA: MIT Press and Washington, D.C.: The American Enterprise Institute for Public Policy Research, 1994).

16 The service delivery configuration of a nontraditional retail customer begins at the generation site and ends at its location. The generation company is responsible for bringing the electric power to the transmission network or grid, and hence, the generation company purchases transmissionaccess service from the transmission service provider. The nontraditional retail customer is responsible for arranging for the transportation of the electric power over the transmission grid and over the local distribution company's facilities. It fulfills these responsibilities by purchasing transmission service from the transmission service provider and distribution access and distribution services from its host local distribution company. Therefore, inefficient price increases for unbundled transmission and distribution services make it more difficult for retail customers to remain or become nontraditional. 
control of diverse sets of generation resources, the balancing of interlocking transmission networks, and varying levels of consumer load. ${ }^{17}$ With respect to the pricing of generation services, the new communication technologies hold out the promise of interactive connections between generation companies and distribution companies. Information freely flowing across these connections makes it easier for the generation companies to set prices for generation services that vary in real time. ${ }^{18}$

Of course, the deployment of advanced information-processing technologies is not dependent on the introduction of real-time prices. Uniform rates, seasonal rates, time-of-day rates, and volume-discounted rates are still relevant. Similarly, economic development rates and antibypass rates still have a role to play in implementing public policies. However, the systematic removal of entry barriers to the generation market through information technologies does precipitate some changes in the way bundled retail services and unbundled generation services are priced. Market-based prices are set for competitive generation services. Downwardly flexible prices dominate the pricing structures of the emergingly competitive bundled retail services. Prices subject to prior regulatory approval are used for the noncompetitive bundled retail services. ${ }^{19}$

The acceptance by regulatory authorities of market-based prices for competitive generation services hinges on the presumption that the generation market is sufficiently competitive to cause cost and price reductions. Everyone is

${ }^{17}$ Division of Strategic Planning, "Perspectives on the Past, Strategies for the Future," 15, ก. 11.

18 Instantaneous prices provide interested retail customers with the information necessary to manage the use of electricity more effectively. More effective electricity use, in turn, lowers production costs as altered consumption patterns at the retail level enable the utility to use its resources more efficiently.

${ }^{19}$ It is demonstrated in subsequent sections of this paper that this trichotomy is favorable to the maintenance of social goals by the utility. 
happy when there are cost and price reductions. Society is pleased because it is incurring less costs to produce the nearly optimal amounts of generation services. Consumers are happy because they are consuming more of the generation services at lower prices. Stockholders are pleased because they are earning a competitive rate of return on their investments. In effect, under the appropriate conditions, market-based prices are blessings.

The market's reaction to downwardly flexible prices is another story. Society, in general, is happy because the regulated company is responding to competitive pressures. Some consumers are happy because they are consuming more of the emergingly competitive services at lower prices. However, the utility's stockholders may not be happy. By definition, downwardly flexible prices, at some time or another, will lie somewhere between the prices that were approved beforehand by regulatory authorities and the average incremental costs of the particular services. Consequently, sooner or later, the utility will experience changes in its revenues and costs, as it lowers the downwardly flexible prices to ward off competitors. When the market demand schedules for the affected services are elastic as might be expected, the price reductions cause increases in the utility's revenues and costs. If the changes in net revenues due to the price reductions are positive, then stockholders are happy with downwardly flexible prices for emergingly competitive services. If, however, the changes in net revenues are negative, the stockholders may not be happy for the following reason. The downwardly flexible prices may cause reductions in net revenues that are greater than the reductions that would occur if the utility simply losses the affected customers.

Without regard to the feelings of the stockholders, it should be clear that the utility does not expect to increase its profitability by voluntarily lowering its downwardly flexible prices. If the utility expected to increase its profitability through voluntary price reductions, the typical customers, who are enjoying downwardly flexible prices, would not have to threaten to go elsewhere. 
Consequently, there is a strong possibility that downwardly flexible prices will cause a reduction in the utility's profitability. ${ }^{20}$

It should be apparent that the responsibility for the maintenance of social goals cannot be assigned indiscriminately to the utility's generation companies without adverse consequences. Higher generation prices, set to recover the costs of maintaining social goals, represent threats to the survival of the utility's generation companies. The distinguishing characteristic of an "at risk, " utilityowned generation company is that its production costs and generation prices are too high in relation to other generation companies in the market. Therefore, the threatened utility-owned generation company begins a round of cost cutting and price declines in an effort to regain its competitive position. It does not raise or hold constant its generation prices to maintain social goals.

It is natural that an at risk, utility-owned generation company would turn to cost cutting and price reductions in an effort to survive after industry reform. This company may choose to lower its prices for its elastic generation services, which means that its gross revenues and costs would increase. If the additional costs of producing more of these elastic generation services are rising more slowly than the additional revenues from the increased sales of these services, then the at risk generation company's profits are rising at a rate determined by the positive rates of changes of revenues and costs. Consequently, this utility-owned generation

\footnotetext{
${ }^{20}$ For many, the ill effects of a reduction in the utility's profitability are more than offset by the benefits of a more competitive generation market. A more competitive generation market means that larger numbers of generating companies are producing larger and more diverse sets of comparable electric power services. This competition puts pressure on the utility to lower the prices for its generation services. As a result, large-volume consumers of electric power or their agents are able to purchase electricity at substantial discounts from existing retail rates. If these large-volume customers are commercial or industrial companies, the lower prices for generation services may be passed through to consumers in the form of lower prices for those goods and services produced by the commercial and industrial companies.
} 
company does not have to experience a decline in its profitability after industry reform. $^{21}$

Still, it may be the case that the profitability of the at risk utility-owned generation company falls after the introduction of more competition into the generation market. Consider the dilemma facing the utility-owned generation company when either marginal costs are increasing faster than marginal revenues or the company produces only generation services with inelastic market demand schedules. In both instances, the profitability of the utility-owned generation company falls when it has to lower prices for generation services. With respect to generation services with inelastic market demand schedules, the rate of change of revenues is negative, and the rate of change of costs is positive. Therefore, profits must fall. Consequently, regulatory authorities would find it to be difficult to continue to use the generation market as a source of funds for the maintenance of social goals.

Reduced profitability is not the only cost that can be associated with competitive generation services. If the utility does not recapture its profitability through sales growth in the generation market, it may want to boost its prices for noncompetitive regulated services. For example, the utility may want to increase the prices for its unbundled transmission-access services or bundled retail services. Usually, such price increases assist the utility in regaining its profitability because the market demand schedules for these services typically are inelastic. However, increases in the prices of transmission-access services may induce some wholesale customers to become self-generators. Additionally, these price increases might induce large-volume customers to fly from the utility's service territory. Self generation and flight create new threats to the utility's profitability that offset some of the gains in profitability caused by increasing the prices of the noncompetitive

21 The utility's profitability declines when the additional costs of producing generation services with elastic market demand schedules exceed the additional revenues generated by the additional sales of these services. 
transmission-access services. Hence, the utility may look to increase the prices of bundled retail services. Unfortunately, rising rates and charges for these bundled services precipitate complaints that small-volume customers cannot be insulated fully from price increases due to industry reform. Furthermore, price increases for bundled retail services may induce the utility to scale back its efforts to maintain social goals.

\section{CHANGING FOCUS TO MAINTAIN SOCIAL GOALS}

Undoubtedly, regulatory authorities will be roundly criticized if they implement an industry reform that makes it too costly for the utility to maintain any social goals. For example, consider a reform proposal that is based on open access to the utility's transmission network. A working definition of open access is that any generation company can use unbundled transmission-access features and functions to connect itself in its desired fashion to the utility's transmission network, while the utility uses unbundled transmission-interconnection features and functions to connect its transmission network to the transmission grid. However, these access and interconnection options do not yet exist because the existing transmission networks and grids were not designed to provide these unbundled features and functions. Therefore, it is possible that it will be very costly to convert the existing closed transmission systems into new open transmission systems. ${ }^{22}$ If the conversion costs of open access for the electric power industry are high enough, they can overtake the cost savings from a competitive generation

\footnotetext{
22 It has been far from inexpensive to implement the telecommunications industry's version of open access. Who is there to say that the implementation of the electric power industry's version of open access will not be equally expensive?
} 
market, regardless of how these cost savings are distributed. ${ }^{23}$ Therefore, it should be apparent that open access does not guarantee that there will be cost savings left over to dedicate to the maintenance of social goals.

It seems that a reform effort based on open access needs to be peppered with measures that increase the probability that the utility will be able to maintain social goals. These measures can come into being if the utility's regulators are willing to change the focal points of their public policies. For example, regulatory authorities can be more selective with respect to the mechanisms that they choose to use to maintain social goals. The staff of the California Public Utilities Commission suggested the elimination of the Electricity Rate Adjustment Mechanism for retail customers because it is a nondiscriminating means to remove any disincentives to demand-side management. ${ }^{24}$ As a substitute, the staff suggested a Net Lost Revenues Adjustment Mechanism that discriminates less imperfectly between revenue losses attributable to the use of demand-side management techniques and revenue losses attributable to other causes. ${ }^{25}$ Because the Net Lost Revenue Adjustment Mechanism allows only for the recovery of lost revenues attributable to demand-side management, it has the potential to make the utility more cost conscious when it deploys its demand-side-management technologies. Additional emphasis on cost control should reduce the costs of substituting demand-side management for the production of electric power.

23 Sometimes, the expectations of regulators are stronger than merely hoping to see reductions in prices of final goods and services. The California Public Utilities Commission wants to see significant reductions in the prices of generation services if a proposal to reform the industry is implemented. It also wants to see these price reductions converted into reduced prices for final goods and services. See: Before the Public Utilities Commission of the State of California Order Instituting Rulemaking on the Commission's Proposed Policies Governing Restructuring California's Electric Services Industry and Reforming Regulation filed with the Public Utilities Commission April 20, 1994 R. 94-04-031, 20.

24 Division of Strategic Planning, "Perspectives on the Past, Strategies for the Future," 54. 25 Ibid. 
Regulatory authorities are not only aware of the significant private costs of demand-side management, they also are aware of the problems that can be created for the utility when there are significant industry-reform costs. They know that large-volume electricity users will try to avoid these costs whenever possible. They know that these users are not shy about threatening to leave the utilities under the regulators' jurisdiction because low-priced, comparable electric services are available elsewhere. So, what if large-volume users actually did leave regulatory jurisdictions because of the costs of industry reform? Regulatory authorities would need to address how these profits might be recovered so that the utility can maintain social goals.

A change in focus that could assist in the maintenance of social goals is for regulatory authorities not to be overconcerned about lost profits. Although fewer barriers to entry into the generation market do pose threats to the utility's overall profitability, these threats do not necessarily make it impossible for the utility to maintain social goals. Regulatory authorities can shift their attention to inducing cost reductions from the utility in an effort to make it possible for the utility to maintain social goals.

Regulatory authorities have a variety ways to induce the utility to reduce its costs. They can use incentive regulation to induce the utility to reduce the operating costs of the utility's transmission and distribution companies. ${ }^{26}$ Incentive regulation also is useful for scaling back the utility's management ranks. But, there is a problem with using the incentive regulation of transmission and distribution markets to provide the net revenues that will be diverted to the maintenance of social goals. The logic behind incentive regulation is not completely compatible with the maintenance of social goals. Incentive regulation works to its fullest

${ }^{26}$ Although incentive regulation is applicable for the utility's generation companies when they are under attack from nonutility generators, the utility would be hard pressed to use any resulting cost savings to maintain social goals. These cost savings would have to be dedicated to combating the competition in the generation market that is provided by the nonutility generators. 
extent only when the utility has the full opportunity to increase its stockholders' values. A less-than-full opportunity to increase the stockholders' values diminishes the force of incentive regulation. Obviously, the use of the profits from incentive regulation to maintain social goals represents a suboptimal opportunity for the utility to increase its profitability. Consequently, regulatory authorities will have to determine whether they can rely only on the incentive regulation of the utility's transmission and distribution companies to maintain social goals.

If regulatory authorities determine that incentive regulation is not enough to maintain social goals, they always can realign the pricing of noncompetitive services. Regulatory authorities have some leeway in this area. They do not as a rule set prices for these services that permit the utility to earn supranormal profits when threats to the utility's profitability are absent. Consequently, they can assist the utility with its effort to maintain social goals by approving higher prices for noncompetitive services.

It is clear that regulatory authorities have ways to assist the utility in its effort to maintain social goals after industry reform. However, their options do not only build a foundation for the maintenance of social goals. They also make it more difficult for an industry reform to achieve its objectives. For example, the removal of barriers to entry into the generation market is supposed to promote competition in this market. But, inefficiently high prices for transmission-access services can keep some nonutility generators out of the market. Furthermore, downwardly flexible regulated rates, involving the cross subsidization of bundled electricity services for large-volume users, also can inappropriately keep out some nonutility generators. Finally, the recovery of this subsidy from small-volume users, who are not threats to leave the utility, helps to slow down the pace of industry reform. Therefore, regulatory authorities are between a rock and a hard place with respect to the maintenance of social goals when the removal of entry barriers into the generation market requires the utility to lower its generation prices without sufficient assurances that it will be able to maintain its profitability. 


\section{USING UNBUNDLED TRANSMISSION AND DISTRIBUTION SERVICES TO MAINTAIN SOCIAL GOALS}

The analysis in the preceding section has demonstrated that the demand and cost characteristics of the post-reform generation market may have adverse effects on the utility's ability to maintain social goals. Fortunately, the removal of entry barriers to the generation market is consistent with regulatory policies for unbundled transmission and distribution services that enable the utility to maintain social goals. Regardless of how wholesale or retail customers obtain their unbundled generation services, they will purchase system operation, transmissionaccess, transmission, and distribution services from their host utilities and no one else. ${ }^{27}$ That is, the post-reform transmission and distribution markets are expected to remain monopolistic or nearly so in the near term. ${ }^{28}$ Consequently, the unbundled transmission and distribution services produced for sale in these markets are candidates for providing financial support for the maintenance of social goals. How might this financial support be provided when the prices for unbundled services are set under incentive regulation?

Suppose that the utility wants the pricing flexibility embedded in incentive regulation to apply to all of its unbundled transmission and distribution services. Suppose that the competitive annual rate of return for the utility's investment assignable to unbundled services is 10 percent. Assume that the sum of the utility's assignable investment to unbundled transmission and distribution services

${ }^{27}$ More likely than not, these three regulated classes of services will be provided in two ways. They will be bundled for those customers that elect to buy end-to-end electricity services from their distribution companies, or they will be unbundled for those customers that decide to purchase generation services directly in the generation market. Unbundling provides customers with the opportunity to pick and choose the features and functions that they need to efficiently transport and deliver electric power to their premises.

${ }^{28}$ Of course, system operation, transmission and distribution services do not have to be purchased from the utility when the wholesale or retail customer with distribution capabilities chooses self generation over third-party-produced electric power. 
is constant annually at $\$ 100,000,000$. Assume that the sum of the utility's annual operating and other costs for the unbundled transmission and distribution services is constant at $\$ 50,000,000$ when the utility does not have to maintain social goals. Assume that sum of the social-goal costs, operating costs, and other costs, is equal to a constant $\$ 59,000,000$ when the utility has to maintain social goals. Assume that the utility's constant annual cost of supporting social goals equals $\$ 10,000,000$. Finally, assume for ease of illustration that each unbundled service in the transmission and distribution markets has an inelastic market demand schedule. Under these assumptions, the utility experiences a $\$ 1,000,000$ reduction in the operating and other costs for the unbundled transmission and distribution services when the utility has to provide financial support for the maintenance of social goals. These assumptions also imply that the utility cannot obtain additional revenues from the unbundled transmission and distribution services by lowering the prices for these services.

The social-goal cost of $\$ 10,000,000$ can be described as an avoidable cost of production that is shifted completely to unbundled transmission and distribution services. Because the costs of producing these services have increased and the market demand schedules for these services are inelastic, the utility has to increase their rates to cover the social-goal cost. As a result, the consumption of these unbundled services falls. The assumed effect on operating and other costs, attributable to the decrease in consumption, is $\$ 1,000,000$. Consequently, the utility has to come up with a configuration of rates for unbundled transmission and distribution services that yields $\$ 9,000,000$ of additional net revenues to maintain social goals.

Alternatively, the $\$ 10,000,000$ social-goal cost can be described as diversion of the utility's rate of return away from stockholders. The return in question is the rate of return on the sum of the utility's transmission and distribution investments assignable to unbundled transmission and distribution services. This rate of return is partially diverted to the maintenance of social goals. In this representation, the 
costs of maintaining social goals are not viewed as avoidable production costs. Instead, they are viewed as creatures of public policy that have to be covered by the stockholders' profits. As a result, the utility is required to earn 10.9 percent on the sum of the transmission and distribution investments assignable to unbundled transmission and distribution services to provide the $\$ 9,000,000$ of net revenues that are required to maintain social goals. However, the utility is allowed to keep only the profits associated with a 10 percent rate of return for its stockholders. Consequently, the maintenance of social goals is viewed as a drain on the utility's profitability from the perspective of the utility's stockholders. Simply put, the regulatory authorities have approved a configuration of rates for unbundled transmission and distribution services that would provide stockholders with a higher overall rate of return, if the regulatory authorities would not require the utility to provide financial support for the maintenance of social goals.

The additional net revenues are forthcoming when the sums of the prices for unbundled generation, transmission, distribution, and ancillary services exceed the compensatory prices for comparable bundled electricity services. ${ }^{29}$ Of course, it is assumed in the calculation of compensatory prices that the utility does not have to provide financial support for the maintenance of social goals. This price relationship allows the utility to increase the compensatory prices of its bundled retail services without encountering the threat of buyers of bundled retail services switching to unbundled services. In effect, the costs incurred to maintain social goals are covered by charging regulated rates for bundled retail services, and unbundled

${ }^{29}$ By definition, compensatory prices are subsidy-free prices that permit the utility to earn revenues that are not expected to exceed the utility's fair, just and reasonable total cost of production. This concept of total cost of production is based on two assumptions. First, regulatory authorities, in some sense, can ensure that the regulated company is earning a competitive rate of return on a reasonable level of investment. Second, regulatory authorities, in some sense, can ensure that the utility's operating and other costs are reasonable. Therefore, compensatory prices are fair, just and reasonable prices in the context of traditional regulation. In other words, a regulated company is not supposed to earn any level of monopoly profits when prices are compensatory. See: Gerald Faulhaber, "Cross-Subsidization: Pricing in Public Enterprise," American Economic Review 65 (1975): 966. 
transmission and distribution services that may be classified as supracompensatory. The recovery outlook, pertaining to the costs of social goals, is less inviting to the utility when the aforementioned compensatory prices for bundled retail services are above the sums of the market-based prices for unbundled generation services, and the supracompensatory prices for unbundled transmission, distribution, and ancillary services. In this instance, the utility has its hands full trying to cover the fair, just, and reasonable costs that are incurred in the actual production of bundled retail services without having to worry about covering the costs that are incurred to fulfill legislative mandates that obligate the utility to maintain social goals. ${ }^{30}$

How might compensatory or supracompensatory prices for bundled retail services be made less than the sum of the market-based and supracompensatory prices for comparable configurations of unbundled services? After industry reform and the incentive regulation of unbundled transmission and distribution services, the utility has the power through pricing flexibility to adjust the rates for unbundled transmission, distribution, and ancillary services. ${ }^{31}$ The utility's power to adjust these rates is considerable because the post-reform markets for transmission, distribution, and ancillary services are monopolistic. Consequently, under incentive regulation, the utility may be in the position to raise the rates for these unbundled services to supracompensatory levels that push the delivered prices of configurations of unbundled services above the compensatory or supracompensatory prices for comparable bundled retail services.

${ }^{30}$ Two legislative mandates in California are enhancing resource diversity and maintaining environmental quality. Recognizing the power of a legislative mandate, the staff of the California Public Utilities Commission has noted that any proposal to restructure the electric industry has to conform to any legislative mandates that are in effect at the time that the proposal is submitted to regulatory authorities for review. See: California Advisory Staff, "Options for Commission Consideration," 36.

31 The prices for generation services are set by market forces. 
If, under incentive regulation, the transmission and distribution markets remain natural monopolies for all relevant price increases and output levels, then there are not any problems with respect to the continued maintenance of social goals by the utility. The utility with the tacit approval of the regulatory authorities simply raises, in tandem, the prices for bundled retail services and the prices for unbundled transmission, distribution, and ancillary services to supracompensatory levels that yield enough additional profits to cover the costs of social programs. This utility does not have to worry about any adverse economic effects because its transmission and distribution companies are still the most economical ways to produce and sell bundled retail services and unbundled transmission and distribution services.

\section{PRICE LIMITS ON UNBUNDLED TRANSMISSION AND DISTRIBUTION SERVICES}

A natural monopoly exists when production by a single firm is the best way to meet market demand at the market-determined, profit-maximizing price. "Best" means that a single company is the lowest-cost way to produce the unregulated, profit-maximizing level of output. Obviously then, a natural monopoly can disintegrate "naturally" when there is a sufficient increase in the demand for the service. In this instance, the cost schedules of competing companies and the new market demand schedule for the service imply that it is less expensive for two or more unregulated, profit-maximizing companies to produce the level of output that is necessary to satisfy market demand. Intuitively, it can be imagined that the increase in demand has pushed the former natural monopolist into rapidly rising portions of its marginal-cost and average-cost schedules. In addition, a natural monopoly can dissolve naturally when a new technology alters the industry's cost characteristics. In particular, the new technology lowers significantly the marginal and average costs of producing small quantities of the service under consideration. 
However, a natural monopoly also can vanish "unnaturally" when the total costs of the natural monopolist are artificially increased..$^{32}$ In this case, the natural monopolist experiences a cost increase that shifts all of its cost schedules upward, causing the cost schedules of its smaller potential competitors to look more attractive in terms of a decision on the part of these companies to enter the market. In fact, the smaller companies actually can compete with the natural monopolist on the basis of prices when the artificial cost increases are large enough.

The possibility that a natural monopoly can vanish unnaturally suggests that the prices for the unbundled transmission and distribution services under consideration have upper limits. These limits are encountered when the artificially increased cost levels cause the unnatural disintegration of the utility's natural monopolies in transmission and distribution. How does this occur? As the costs of unbundled transmission and distribution services continue to be artificially pushed up, the economic viability of the monopolistic distribution and transmission companies is threatened by alternative transmission and alternative distribution companies. The basis for this threat is that the alternative companies can exploit the artificially high costs for unbundled transmission and distribution services caused by the utility's obligation to implement legislative mandates. ${ }^{33}$ In other words, the alternative transmission and distribution companies can profitably set prices for their unbundled transmission and distribution services that are lower than

32 The utility's obligation to implement legislatively mandated social programs is the source of such an artificial increase in its costs.

${ }^{33}$ Self generation also comes closer and closer to being a viable economic alternative for larger and larger numbers of the utility's customers. While this outcome does not destroy the utility's natural monopolies in transmission and distribution, it does complicate the utility's effort to compete profitably in the generation market. 
the prices that the utility-owned transmission and distribution companies must set for the full recovery of the artificially high costs that are included in their comparable unbundled services.

The price limits for unbundled transmission and distribution services are most troublesome to regulatory authorities when the removal of entry barriers to the generation market causes the utility to bear additional private costs such as the fixed costs of facilities that have become obsolete because of this particular industry reform. Regulatory authorities may decide that the utility should be granted the opportunity to fully recover these stranded costs. However, the maximum prices for unbundled transmission and distribution services may not provide enough net revenues. In this case, the utility cannot make good on its opportunity to fully recover stranded costs even though it is subject to incentive regulation of transmission and distribution services. Consequently, the utility cannot make good on the opportunity that the incentive regulation of these services provides for it to maintain an acceptable level of overall profits for its stockholders.

The price limits on unbundled transmission and distribution services also may be encountered when the utility is required to invest in new communications and transmission facilities to accommodate the introduction of more competition into the generation market. More cost-effective transmission facilities and advanced communications facilities are big-ticket items, which raise the possibility that the finite distances between existing prices for unbundled transmission and distribution services and their upper limits may not be sufficient to meet all public-policy objectives.

New investments in the electric power industry's transmission infrastructure may have to play second fiddle to the recovery of stranded costs. The recovery of stranded costs, in turn, may have to give way to continued financial support for the maintenance of social goals. Other possibilities most likely suggest themselves to the reader. Consequently, the regulatory authorities have to assess the price limits for unbundled transmission and distribution services before they can make any 
decisjons relating to the maintenance of social goals. This assessment will reveal whether the utility has the wherewithal to unabatedly continue to maintain social goals without having to raise the prices for bundled retail services.

\section{SIX MECHANISMS FOR THE MAINTENANCE OF SOCIAL GOALS}

Thus far, numerous factors were identified that threaten legislative and regulatory efforts to use the utility to maintain social goals. On the public-policy side, the ill-advisability of shifting costs to the competitive generation market and the basic incompatibility of the logic behind incentive regulation with the maintenance of social goals were raised. The inherent price limits on unbundled transmission and distribution services and inopportune demand and cost characteristics in the generation market were noted as economic threats to the maintenance of social goals. The drain on profitability caused by the maintenance of social goals and the need to fully recover stranded costs make the stockholders reluctant to maintain social goals. The responsibilities of maintaining the utility's profitability and providing an environment that is suitable for investment in new communications and transmission infrastructure were recognized as regulatory problems with respect to the maintenance of social goals. ${ }^{34}$ Each of these eight factors plays a role in the selection of mechanisms that are capable of maintaining

${ }^{34}$ The staff of the California Public Utilities Commission has considerable experience with using the regulated utility to implement and maintain social goals. They suspect that the maintenance of social goals will become more difficult as the electric power industry becomes more competitive. On this basis, the California Staff has suggested that the California Legislature might want to consider modifying some of its mandates. A candidate in this regard is the legislative mandate applicable to renewable resources. This mandate guarantees the deployment of a prespecified amount of renewable resources regardless of the impact on electric service prices until the value of fuel diversity can be reliably estimated. See lbid. In addition, the staff has identified four utility activities that help to support social goals. They are: (1) promotion of low-emission vehicles (pollution goal), (2) subsidized rates for economic development (economic growth goal), (3) assistance programs for low-income customers (welfare goal), and (4) universal service to a basic, affordable package of up-to-date electric services (equity goal). The Staff feels that the utility should not be solely responsible for supporting these activities. Ibid., 56 . 
social goals. However, they are not the only factors that influence the selection of a maintenance mechanism for social goals. This decision needs to be consistent with holding down the costs and prices of bundled retail services and avoiding anticompetitive behavior by the utility. For example, an acceptable mechanism would not involve cross subsidization of large-volume wholesale users by smallvolume retail users.

In addition, the regulatory authorities have to worry about the complexity of the chosen maintenance mechanism. Obviously, the selection of a maintenance mechanism requires more effort as the number of social goals becomes larger. Furthermore, the design of a mechanism may become more demanding when it has to accommodate a larger number of social goals. Six mechanisms, shown in Table 2 , are analyzed in this section. Only one mechanism requires a noticeable departure from current regulatory practices. That mechanism is to use general tax revenues to maintain social goals. It relieves the utility of its current responsibilities to collect and distribute monies to maintain social goals, and it places these responsibilities on a government agency. ${ }^{35}$

The next mechanism is an upfront, lump-sum fee that is assessed against all participants in the competitive generation market. This fee cannot be avoided by restricting a nonutility generator's operations to wholesale or retail transactions. Furthermore, it cannot be avoided by taking a utility-owned company out of a regulated market and putting it into a deregulated market. Finally, it cannot be avoided by relieving a utility-owned generation company of its current responsibility to support the market for bundled retail services and by ordering the utility to

35 Is there a real possibility that a government agency would take on these responsibilities? The practical answer seems to be no. A casual reading of the newspapers indicates that existing tax rates are neither inconsequential nor well-received. This observation suggests that it would not be easy to raise taxes for the purpose of maintaining social goals that presently are the responsibility of the utility. 
TABLE 2

Characteristics of Mechanisms to Support Social Goals

Mechanism

Characteristics

General Tax Revenues

Lump-sum Fee

Expanded Lump-sum Fee

Exit Fee

Usage-based Surcharge

Surcharge on Demand
Government agencies directly responsibility for social goals; not likely to be implemented because of public opposition to higher taxes.

Unavoidable fee paid by all generation companies; fee economically and administratively intrusive.

Unavoidable, economically and administratively intrusive fee paid by all generation, transmission and distribution companies.

Fee paid by any customer who purchases electric power from a nonutility generator; fee may be perceived as a penalty.

Surcharge completely sustainable when customers cannot leave existing host utility and substitutes never exist for surcharged services; nearly completely sustainable when customers can leave existing host utilities and substitutes never exist; may not be sustainable when substitutes exist.

Large-volume users support social goals; smallvolume users do not directly support social goals; utility profitability may be reduced; sustainable when existing and potential large-volume customers cannot leave the utility's service territory and no substitutes for surcharged services ever available.

Source: Author's construct. 
compete in a competitive wholesale market, which is the case with the formation of exempt wholesale generators by a utility.

However, the unavoidability of this fee also is its weakness. This fee is intrusive in terms of economics and administration because it is assessed against self-generators, cogenerators, independent power producers, exempt wholesale generators, municipalities, rural cooperatives, and investor-owned utilities. ${ }^{36}$ Economically, it expands the responsibility for the maintenance of social goals to nonutility generators. If it is assumed that the dollar value of maintaining social goals does not change with the fee's implementation, then its effects are to reduce the total costs of the utility-owned generation companies and to increase the total costs of nonutility generators. Depending on the demand elasticities facing the utility-owned generation companies, some or all of their cost reduction are flowed through to wholesale and retail customers. For the same reason, some or all of the nonutility generators' higher costs are passed on to their customers. Therefore, under the assumption of all other things remaining the same, the utility-owned generation companies are in a position to offer price reductions to their customers. These price reductions in conjunction with the induced price increases for nonutility generators may cause some of the latter type of companies to exit the generation market prematurely. Administratively, this lump-sum fee requires the utility to develop the means to collect yet another periodic payment from their competitors.

${ }^{36}$ A fee-based maintenance mechanism has been used with some success in the telecommunications industry. During the process of setting access charges for interstate longdistance carriers, the Federal Communications Commission instituted a fee-based fund to support high-cost utilities serving primarily rural areas. Additionally, the Federal Communications Commission instituted a Universal Service Fund to ensure basic telecommunications service at reasonable cost to all the consumers who want that service. Also, the New York Public Service Commission has instituted a replica of the Federal Communications Commission's Universal Service Fund to ensure that local competition does not result in unaffordable local basic service. 
This will likely lead to some stirring and costly regulatory debates. An important issue in these debates will be how to ensure that the fee is fairly determined for all electricity users. This issue exists because the fee is paid initially by the utility and its competitors.

Another mechanism, closely related to the lump-sum fee, is to expand the concept of burden sharing to the providers of unbundled transmission and unbundled distribution services. The lump-sum fees, now collected from companies operating in all of the post-reform markets, would be paid into a Social Goal Support Fund that is administered by a party that is neither a generation, transmission, nor distribution company. The sizes of the lump-sum fees for generation, transmission and distribution companies would be calculated using some measurable criteria that the affected regulatory authorities deem to be suitable for the purpose of apportioning the responsibility for the maintenance of social goals to different markets of the electric power industry. The criterion could be total annual sales, the number of customers served, or some mixture of these two criteria.

The fourth mechanism is an exit fee that is paid by the utility's former customer when that customer leaves the utility to purchase the services of a nonutility generator. The concept behind this fee is similar to the concept behind the lump-sum fees: no targeted class of companies or customers should be able to avoid contributing to the maintenance of social goals simply by opting out of the services provided by the regulated company. However, the economic effects associated with the exit fee are different from the economic effects associated with the lump-sum fees. The lump-sum fees are paid by the producers, transmitters, and distributors of electric power. If these companies are unregulated and profit maximizing, then these fees are not passed on to their customers because these fees have all the characteristics of a profit tax. If these companies are regulated and not profit maximizing, then these fees, in whole or in part, may be passed on to their customers because the regulatory authorities can approve rate increases for 
this purpose. Meanwhile, an exit fee is paid by the retail user of electric power. ${ }^{37}$ If the retail user is a residential user, then there is no one to pass the cost onto. If the retail user is a business customer, then the exit fee can be amortized or passed on in whole or in part. Therefore, an exit fee appears more onerous from the perspective of consumers than lump-sum fees paid by companies because it makes economic life more difficult for specific retail customers.

In effect, it seems that an exit fee is more of a penalty than a cost-recovery mechanism. To see why a commercial or industrial customer might have this perception, consider a customer of either type that is prevented from leaving the utility because the exit fee is too high. The options available to this customer are to raise the prices of the goods and services that it sells outside of the electricity market, cut its costs, combine cost cutting and price increases, or go out of business. Suppose that the customer in question cannot raise its prices for competitive reasons. Therefore, this customer must cut its costs. It can accomplish this feat by reducing its electricity consumption, its payroll, or its travel. Suppose that the customer does all three. The effect of reduced electricity consumption is to lower the utility's revenues and perhaps profits. The effects of a reduced payroll and travel is to restrain the economic growth and development of the customer's business. It is reasonable for the customer to perceive each of these outcomes as a penalty that has been induced by the exit fee.

Another mechanism, suitable for supporting social goals, is usage-sensitive surcharges on retail services that are sold to small-volume electricity users and on the unbundled transmission and distribution services that are sold to large-volume electricity users. This mechanism works as long as there are not substitutes for the

${ }^{37}$ An exit fee can take on a variety of forms. It could be a uniform charge that is assessed against all leaving customers. In this case, large-volume customers would be more likely to leave the utility than small-volume customers. Alternatively, the exit fee could be a schedule of charges that increases by usage level. In this way, large-volume users would be discouraged from leaving the utility. However, a sliding schedule of charges may act to discourage the economic growth of existing businesses. 
small-volume retail services and the unbundled, utility-supplied transmission and distribution services. In other words, neither small-volume nor large-volume electricity users are in the position to leave their current host transmission and distribution companies. Consequently, they cannot avoid paying the surcharges.

Clearly, the unavoidability of surcharges can be challenged when customers can leave their host utilities' service territories or become self generators. To have a chance of avoiding either outcome, the utilities in question have to agree to nationwide and relatively low usage-sensitive surcharges on the prices of unbundled transmission and distribution services. However, low and nationwide surcharges may not be enough to avoid successful challenges of the unavoidability of the surcharges. Even low surcharges might invite nonutility companies to produce substitutes for unbundled, utility-supplied transmission and distribution services. Either these substitutes will gain a foothold in the markets for unbundled transmission and distribution services, or they will disappear after a brief period of driving down the prices of the unbundled transmission and distribution services supplied by the utility. In either case, the unavoidably of the surcharges has been successfully challenged.

It should be clear that the unavoidably of usage-sensitive surcharges placed only on the utility's wires has been successfully challenged when nonutility suppliers of unbundled transmission and distribution services, in some sense, are competing with the utility's transmission and distribution companies. It may not be as clear that the unavoidability of the surcharges on the utility's wires has been successfully challenged when the nonutility suppliers do not gain lasting footholds in the transmission and distribution markets. To make this point, it should be sufficient to note that a successful challenge to the utility's pricing strategy occurs when: (1) the utility lowers the prices of its unbundled transmission and distribution services to ward off its nonutility competitors, and (2) the utility cannot raise the prices of its unbundled services backup because it fears reentry by other nonutility suppliers of these services. When both of these conditions are satisfied, the 
market has become workably contestable, thereby limiting the use of usagesensitive surcharges on the utility's wires as the means to maintain social goals. In particular, the utility has to lower its surcharges or suffer the loss of customers. The utility's profitability may suffer in either instance. Therefore, it is more difficult for the utility to continue the maintenance of social goals.

Of course, the utility's dilemma can be resolved by regulatory authorities. They can put usage-sensitive surcharges on the transmission and distribution wires that are owned by the nonutility suppliers of unbundled transmission and distribution services. This regulatory action serves to assess usage-sensitive surcharges against all of the participants in the workably contestable transmission and distribution markets. Consequently, this action is very similar to the extension of the lump-sum fees that was suggested earlier. The difference between the two extensions in terms of the scope of assessment is that the lump-sum fees are paid by generation companies, as well as transmission and distribution companies, whereas the usage-sensitive surcharges are extended to include only all of the transmission and distribution companies.

The final mechanism is to dedicate a line item of the demand charge to cover the costs of maintaining social goals. Predictably, with an all-other-things-equal assumption, this new rate element causes large-volume customers subject to the demand charge to pay more to maintain social goals. ${ }^{38}$ Small-volume customers are insulated from any additional responsibility for the maintenance of social goals because they typically do not pay demand charges.

However, this mechanism may present the utility's stockholders with some problems. If the utility is not able to compensate the large-volume customers for

${ }^{38}$ Of course, these customers may not have to pay more overall to the utility when cost savings attributable to the removal of entry barriers to the generation market offset the effects of the new rate element. 
their maintenance of social goals, they will experience a price increase that, in turn, causes a decrease in energy usage by these customers. Because the market demand schedules for large-volume customers usually are elastic, their reduced consumption is associated with reduced revenues for the utility. Clearly, the utility's profitability is reduced when the reduction in its revenues exceeds the reduction in its variable costs of production. In addition, some of these largevolume customers might leave the utility's service territory. It is seldom the case that these outcomes are positively viewed by stockholders.

The direct reduction of its profits and lost customers are not the only problems that the utility might face because of this new rate element in the demand charge. It has just been argued that an increased demand charge precipitates a price increase for the utility's existing large-volume customers. The argument naturally extends to the conclusion that this new rate element precipitates a price increase for all large-volume customers. Therefore, new large-volume customers might be discouraged from entering the utility's service territory. Fewer largevolume customers is an outcome that is not often favorably viewed by chambers of commerce and state legislatures. Typically, new large-volume customers are engines of economic development and sources of employment for their areas. Consequently, any price increases that can be associated with this mechanism would turn this mechanism into a politically unacceptable way to maintain social goals.

What if, the removal of entry barriers is associated with cost savings in the generation market that more than fully compensate large-volume customers for the adverse effects of an increased demand charge? The utility's profits may increase in this case, if the utility is able to decrease its generation costs. Regulatory authorities can use these additional profits from the sale of generation services to maintain social goals. However, there is a cost. The diversion of profits is a reason for the utility not to fully exploit its cost reduction potential in generation. Why? 
The utility does not realize the full benefits of this activity. ${ }^{39}$ Consequently, regulatory authorities may want to think twice about maintaining social goals by the diversion of the utility's profits from the sale of generation services. This practice is a drain on the cost-saving potential that is created by removing barriers to entry into the generation market.

\section{PROPPING UP MAINTENANCE MECHANISMS THROUGH INCENTIVE REGULATION}

There are various reasons why the incentive regulation of the markets for unbundled regulated services can put the utility in the position to maintain social goals. It is well-known that the fundamental reason for incentive regulation is to induce the utility to lower its costs. Furthermore, incentive regulation is associated with profit increases through cost reductions. In these regards, it does not matter whether the utility is or is not subject to competition. In this instance, however, it is known that incentive regulation is being proposed for monopolistic markets. Therefore, the first important assumption of this analysis is that incentive regulation can prop up the six maintenance mechanisms even if the transmission and distribution companies are natural monopolists in their service territories. ${ }^{40}$ This

${ }^{39}$ The basic theorem of incentive regulation implies that the diversion of profits decreases the amount of profit that regulatory authorities have available for this purpose. The line of reasoning behind this claim is not that difficult to understand. The diversion of profit means that the utility gets to keep less of the additional profits than it otherwise would have been able to keep for itself. Since the utility retains a smaller percentage of its additional profits, the utility reduces its costreduction efforts because its payoff is smaller from these efforts. Because the utility holds back on its cost-reduction efforts, there are less additional profits available to divert for whatever purpose.

40 The problem with the assumption that transmission and distribution markets are natural monopolies is that no one knows really whether it is defensible. Entry barriers sanctioned by legislative and regulatory authorities have prevented the testing of the natural monopoly status of these markets. No nonutility transmission company has been allowed to sell transmission services in competition with a vertically integrated utility. It also does not appear that legislative or regulatory authorities are prepared to allow nonutility transmission companies to sell unbundled transmission services in competition with the utility-owned transmission company in a post-reform transmission market. 
assumption ensures that a single-company industry structure is the best way to provide unbundled transmission and distribution services. ${ }^{41}$

The second important assumption is that the transmission and distribution companies control the production of services that cannot be provided by anyone else. This assumption ensures that the transmission company is a dominant firm with respect to all generation companies and those distribution companies that choose not to self-generate. It also ensures that the distribution companies are dominant firms with respect to all customers that must use their distribution facilities.

Dominant firms possess a brand of market power that is more potent than the deep pockets that allow predation and more destructive to the competitive potential of an industry than customer loyalty, customer inertia, product familiarity, and product differentiation. For example, market dominance enables the transmission company to control the behavior of all generation companies and some distribution companies by determining a large percentage of their costs and profitability. ${ }^{42}$ Consequently, dominant firms can continue to maintain social goals without any cost-cutting at all, as long as the post-reform transmission and distribution markets are natural monopolies.

Because dominant transmission and distribution companies can maintain social goals under rate-of-return regulation, the question is: what does incentive regulation add to the behavior of dominant transmission and distribution companies that is not there under rate-of-return regulation? The answer to this question is that these firms now have the incentive to eliminate waste.

\footnotetext{
41 William W. Sharkey, Theory of Natural Monopoly (Cambridge, MA: Cambridge University Press, 1982).

42 William G. Shepherd and Robert J. Graniere, Dominance, Non-Dominance, and Contestability in a Telecommunications Market: A Critical Assessment (Columbus, $\mathrm{OH}$ : The National Regulatory Research Institute, 1990).
} 
Waste is the type of cost that the utility cuts when its head is not on the block. ${ }^{43}$ Waste is presumed to be at its highest when the market is monopolistic. As a result, incentive regulation is good for the utility, even if it is not facing competition in the markets for unbundled transmission and distribution services. But, things that are good do not necessarily happen on their own in markets that are subject to regulation.

In the usual monopoly case, the utility eliminates waste only if it gets to keep more profits. However, in this case, the utility may have another reason to want to eliminate waste. Less waste with respect to the production of unbundled transmission and distribution services can be used temporarily to support the utility's generation companies. That is, the net revenues that the utility gains by eliminating waste is reinvested in the utility's generation companies through the vehicle of temporarily subsidizing the utility's generation services. Therefore, it is not guaranteed that the incentive regulation of the markets for unbundled services will yield the money to maintain social goals. ${ }^{44}$

Consequently, regulatory authorities should not rush to impose incentive regulation on the monopolistic markets for unbundled regulated services. Perhaps, they should wait until after they are convinced that utility-owned generation companies have aggressively cut their costs in an effort to become competitive with nonutility generators. This delay is necessary for two reasons. First, the utility has the motive to subsidize its generation services with profits from its

${ }^{43}$ Waste is the sum of the administrative, overhead, operations, and maintenance costs that the utility did not have to incur in the first place.

44 The sufficient condition for the maintenance of social goals is that the utility's additional profits due to the incentive regulation of the markets for unbundled transmission and distribution services are sufficiently large to provide its stockholders with a competitive rate of return in the generation market, profits to reinvest to ward off competitors, and money to maintain social goals. It is not obvious a priori how much additional profits will be achieved through the incentive regulation of the markets for unbundled regulated services. What is clear is that pure forms of incentive regulation such as price caps without profit sharing or rate-of-return ceilings will produce the most additional profits. Not much more can be said. 
unbundled transmission and distribution services during the period that its generation services exhibit a cost disadvantage vis-a-vis nonutility generators. ${ }^{45}$ This tactic keeps the generation companies profitable while they are putting their houses in order. Second, the utility has the opportunity to subsidize its generation services when the markets for unbundled regulated services are subject to incentive regulation. Incentive regulation, in many instances, has the outcome that the utility earns a higher rate of return on investment than it would have earned under rate-ofreturn regulation. It would be strategically useful for the utility to divert these "extra" profits voluntarily for a short period of time to support its threatened generation companies. ${ }^{46}$ It is easier for the utility to raise money to invest in generation when its generation, transmission, and distribution are profitable, as opposed to unprofitable generation companies and very profitable transmission and distribution companies.

\section{AD HOC REFORM ELEMENTS PROPPING UP MAINTENANCE MECHANISMS}

Incentive regulation of the markets for unbundled transmission and distribution services is not the only way to maintain social goals. Ad hoc elements of industry reform may be able to take on some of this responsibility. Three of these elements are the substitution of a net revenue loss adjustment mechanism for a decoupling mechanism, the repeal of legislative mandates promoting renewable resources, and the buy-out of contracts involving purchased power.

${ }^{45}$ Robert J. Graniere, Almost Second-Best Pricing for a Regulated Transmission Market with Wholesale Competition (Columbus, $\mathrm{OH}$ : the National Regulatory Research Institute, forthcoming).

${ }^{46}$ Regulatory authorities can minimize the amount of extra profits by allowing the resale of unbundled services that are supplied by the utility-owned transmission company. A resale market for these services would allow generation companies to resell transmission access among themselves, and it would allow distribution companies to resell transmission services to each other. These trades would threaten the utility's profits from transmission because resale of this type is a mild form of competition. 
The decoupling of the recovery of the utility's revenue requirement from its sales has a weak incentive structure in regards to cost control. On average, the utility cannot recover any more or any less than its approved revenue requirement for the period in question. Therefore, the utility does not have any incentive to lower its costs to earn higher profits. In addition, the utility's base-line revenue requirement is determined using rate-of-return procedures. Consequently, the utility simply has to convince the regulatory authorities that its costs are fair, just, and reasonable. However, the decoupling mechanism is inexpensive to administer because it essentially is a true-up procedure. A priori, the sum of these two costincreasing effects of decoupling may be large or small.

Supporters of the decoupling mechanism assert that decoupling does not induce the utility to overspend on demand-side management. In addition, they assert that the utility avoids more social and private costs than the private costs that it incurs as a result of demand-side management. Hence, the total cost of implementing decoupling is the sum of the positive cost of administering the decoupling mechanism and the negative net cost of deploying demand-side management. Because the cost of administering the decoupling mechanism is small and the absolute value of the negative net costs of deploying demand-side management is large, supporters conclude that the society saves money by adopting the decoupling mechanism to encourage demand-side management.

Detractors reach a much different conclusion. They assert that decoupling does cause the utility to overspend on demand-side management because the utility is assured the recovery of these costs. They also assert that the private costs to deploy demand-side management are greater than the private costs that are avoided by the deployment of demand-side management. In addition, they assert that the net private costs incurred by the utility to deploy demand-side management are greater than the avoided social costs. Hence, the total cost of decoupling is the sum of the positive cost to administer the decoupling mechanism, the positive cost of overspending on demand-side management, and the positive difference when the 
avoided social costs are subtracted from the net private costs to deploy demandside management. Consequently, detractors conclude that it costs the utility and society money to deploy demand-side management.

The opposing arguments are easily presented in algebraic form. Let $v$ represent the utility's costs to administer the decoupling mechanism. Let $w$ represent the private costs that the utility incurs when it deploys demand-side management and the decoupling mechanism is not present. Let $x$ represent the additional private costs that are induced by the decoupling mechanism. Let $y$ represent the private costs that are avoided by the deployment of demand-side management under decoupling. Finally, let $z$ represent the social costs that are avoided by the deployment of demand-side management. Then, the total cost of demand-side management under decoupling is: $v+w+x-y-z$. Supporters claim that $v+w+x$ is less than $y+z$. Hence, the total cost of demand-side management under decoupling is negative. Detractors claim that $v+w+x$ is greater than $y+z$. Hence, the total cost of demand-side management under decoupling is positive.

The net revenue loss adjustment mechanism has effects that are similar to the effects of decoupling. As before, the utility incurs costs to administer this mechanism. However, it seems that the costs required to administer the net revenue loss adjustment mechanism will tend to be larger than the costs that the utility incurs to administer the decoupling mechanism. Whereas, the utility simply has to establish the correct unrestricted true-up amount under decoupling, the proper administration of the net revenue loss adjustment mechanism forces the utility to focus its attention on avoiding lost profits due to factors beyond the skein of demand-side management and determining the lost profits that are attributable to demand-side management. Also as before, the utility incurs the costs that it would have spent on demand-side management, if the net revenue loss adjustment mechanism was not present. The amount of these costs should be the same as the 
amount of costs that the utility would incur to deploy demand-side management, if the decoupling mechanism was not present.

Similar to the decoupling mechanism, the utility incurs the costs that are induced by the net revenue loss adjustment mechanism. These costs would be different from the costs that are induced by the decoupling mechanism, if the implementation of the net revenue loss adjustment mechanism made the utility more cautious or less cautious in terms of deploying demand-side management. They would be the same when the utility deploys the same amount of demand-side management under either mechanism. Also similar to the decoupling mechanism, the utility avoids the private and social costs that are not incurred because of the deployment of demand-side management. Once again, these costs under the net revenue loss adjustment mechanism may be the same, more, or less than these costs under the decoupling mechanism. Finally, the utility experiences an effect under the net revenue loss adjustment mechanism that it does not experience under the decoupling mechanism. The utility now has an incentive to control costs that are unrelated to demand-side management. It is easy to explain why this incentive exists. The lost profits that are unrelated to demand-side management are absorbed in the current period by the utility's stockholders. Consequently, the utility's management has an incentive to minimize or avoid these losses by controlling costs beyond the skein of demand-side management.

Supporters of the net revenue loss adjustment mechanism assert that it makes the utility more cautious in terms of deploying demand-side management. Hence, they expect that the utility will incur fewer demand-side management costs under the net revenue loss adjustment mechanism. Similar to supporters of the decoupling mechanism, they assert that the utility avoids more social and private costs than the private costs that it incurs as a result of demand-side management. Hence, the total cost for this mechanism is the sum of the positive cost of administering the mechanism and the negative net cost of deploying demand-side management. Finally, supporters conclude that the utility saves money by adopting 
the net revenue loss adjustment mechanism to encourage demand-side management.

Detractors have a different view of this mechanism. They assert that it still causes the utility to overspend on demand-side management because the utility is assured the recovery of these costs. They too assert that the private costs to deploy demand-side management are greater than the private costs that are avoided by the deployment of demand-side management. Also, they assert that net private costs incurred by the utility to deploy demand-side management are greater than the avoided social costs. Hence, the total cost of the net revenue loss adjustment mechanism is the sum of the positive cost to administer the decoupling mechanism, the positive cost of overspending on demand-side management, the positive difference when the avoided social costs are subtracted from the net private cost to deploy demand-side management, and the negative cost induced by the incentive to control costs beyond the skein of demand-side management. As usual, detractors would like to claim that it costs the utility and society money to deploy demandside management.

The opposing arguments also can be presented in algebraic form. Let $u$ represent the cost savings unrelated to demand-side management that are induced by the net revenue loss adjustment mechanism. Let $v^{\prime}$ represent the utility's costs to administer this mechanism, where $v$ is less than $v^{\prime}$. Let $w$ represent the private costs with respect to the deployment of demand-side management when the net revenue loss adjustment mechanism is not present. Let $x^{\prime}$ represent the additional private costs that are induced by this mechanism. Supporters would argue that $x^{\prime}$ is less than $x$. Detractors would assert that $x^{\prime}$ equals $x$. Let $y^{\prime}$ represent the private costs that are avoided by the deployment of demand-side management under decoupling. Supporters assert that $y^{\prime}$ is less than $y$. Detractors assert that $y^{\prime}$ equals $y$. Finally, let $z$ ' represent the social costs that are avoided by the deployment of demand-side management. Supporters assert that $z$ ' is less than $z$. Detractors assert that $z^{\prime}$ equals $z$. Then, the total cost of demand-side 
management under decoupling is: $v^{\prime}+w+x^{\prime}-y^{\prime}-z^{\prime}-u$. Supporters claim that $v^{\prime}+w+x^{\prime}$ is less than $y^{\prime}+z^{\prime}+u$. Hence, the total cost of demand-side management under the net revenue loss adjustment mechanism is negative. Detractors claim that $v^{\prime}+w+x$ is greater than $y+z+u$. Hence, the total cost of demand-side management under the net revenue loss adjustment mechanism is positive.

It has just been demonstrated that nothing definite can be said about whether the implementation of mechanisms to encourage demand-side management is better than doing nothing at all. It now is demonstrated that the same is true for the substitution of the net revenue loss adjustment mechanism for the decoupling mechanism. The net revenue loss adjustment mechanism adds another cost savings in the form of $u$. However, this mechanism also adds a cost increase in the form of $v^{\prime}-v$. When $v^{\prime}-v$ is less than $u$, then the detractors of both mechanisms, in a forced choice, should prefer the net revenue loss adjustment mechanism to the decoupling mechanism. The supporters of both mechanisms also should prefer the net revenue loss adjustment mechanism to the decoupling mechanism under this condition. When $v^{\prime}-v$ is greater than $u$, then detractors and supporters of both mechanisms, in a forced choice, should prefer the decoupling mechanism. Consequently, the total cost effect of the substitution of the net revenue loss adjustment mechanism for the decoupling mechanism, a priori, is not certain. However, there is at least the possibility that this substitution can cause the utility to lower its costs and earn more profits. ${ }^{47}$

The repeal of legislative mandates also presents the possibility of creating additional profits for the utility. Consider the set-aside for renewable resources. In addition to promoting the deployment of renewable resources, this set-aside affects

47 The staff of the California Public Utilities Commission suggested the replacement of the Electricity Rate Adjustment Mechanism with a Net Revenue Loss Adjustment Mechanism applicable only to the utility's conservation activities directed toward retail customers that do not directly purchase generation services at competitive rates. 
the utility's costs. To show how this occurs in a post-reform environment, suppose that distribution companies acquire their generation resources through competitive bidding. Prior to the repeal of this legislative mandate, distribution companies would have to participate in a bifurcated competitive-bidding process. One branch of the process determines the winners and losers with respect to the nonrenewable resources, and the other branch does the same for the renewable resources. After the repeal of the set-aside, the distribution companies would rely on all-source, competitive bidding. All-source, competitive bidding minimizes costs, regardless of whether the bidding process minimizes private costs or the sum of private and social costs. ${ }^{48}$

The buy-out of high-cost contracts for purchased power is a means to increase the utility's profits, as long as the utility can deal adequately with paying termination penalties and securing replacement power. ${ }^{49}$ Termination penalties typically are associated with contract buy-outs. They force the utility into making specific financial calculations before they can even consider a buy-out. Standard financial principles indicate that the present value of long-term cost reductions should exceed the present value of the costs of the contract's termination penalties. When this condition is met the utility is at least in a position to benefit from the buy-out of the contract. However, an excess of cost reductions over

48 Of course, a decision to base resource selection on minimizing private cost weights nonrenewable resources favorably in relation to renewable resources. In comparison, the minimization of the sum of private and social cost favorably weights renewable resources relative to nonrenewable resources.

49 The staff of the California Public Utilities Commission notes that many California utilities are attempting to reduce their costs of purchased power by proposing to change the terms and conditions of existing ISO 4 contracts. These utilities want to base their payments for purchased power on their actual avoided costs rather than forecasted fuel prices. They believe that such a change will enhance their competitive position by decreasing their financial exposure from overpriced contracts. See: California Advisory Staff, "Options for Commission Consideration," 46. 
termination penalties does not ensure that the utility will benefit from a buy-out. The utility also has to worry about a suitable substitute for the brought-out contract. These worries can be substantial as is shown in the following three examples.

The first example deals with a distribution company that has entered into a high-cost contract to purchase wholesale power from an independent power producer. The independent power producer is one of many high-cost suppliers of generation. In fact, it is assumed that all of the nonutility generators are high-cost suppliers of electric power. Consequently, the competitive generation market is uniformly high cost. The distribution company pays the independent power producer at the rate of avoided fuel costs plus the avoided capacity costs of the host utility-owned generation company for each kilowatt. The distribution company fully recovers its contract costs from its retail customers in a monopolistic market. What are the distribution company's incentives under these conditions to buy-out or renegotiate high-cost contracts with termination penalties? They are particularly weak for the following two reasons. First, the distribution company does not have any incentive to renegotiate these high-cost contracts because it is not under any pressure to lower its costs as a precursor to lowering its retail prices. ${ }^{50}$ Second, the uniformly high-cost nature of competitive generation services ensures that the distribution company's costs will increase by incurring the termination penalties associated with the buy-out. Why? The competitive generation market does not hold out the hope of offsetting the distribution company's termination penalties with low-cost replacement power.

${ }^{50}$ Of course, the distribution company may want to renegotiate these contracts when it sees low-price competitors on the horizon. In addition, the distribution company may want to renegotiate these contracts when it can earn and retain indefinitely additional profits by lowering its costs. The second reason for renegotiation exists when the distribution company is subject to incentive regulation. The first reason for renegotiation exists when there is a new cost-reducing distribution technology on the horizon. 
The second example also deals with a distribution company that pays avoided fuel costs plus the avoided capacity costs of the host, utility-owned generation company for each kilowatt that it purchases from a nonutility generator. The distribution company fully recovers these payments from its retail customers in a monopolistic market. However this time, the distribution company can purchase replacement power from low-cost nonutility generators. What are the distribution company's incentives to incur termination penalties under these conditions? They are particularly strong. Although the distribution company does not have to ward off competitors in its retail market, the distribution company can reduce its costs by substituting low-cost generation for high-priced generation when the present value of the price differential exceeds the present value of the amortized termination penalty.

The third example demonstrates that the distribution company does not always substitute low-cost generation for high-cost generation. The only change from the previous example is that the present value of price differential between the high-cost and low-cost sources of generation does not exceed the present value of the amortized termination penalty. This condition implies that the full recovery of termination costs would increase the distribution company's cost. This cost increase, in turn, causes the distribution company to increase the prices for its retail services. Consequently, the distribution company does not want to recontract its purchased power because passing over these opportunities means that the distribution company does not have to deal with the fall-out of unnecessary price increases.

These three examples show that the buy-out of high-priced contracts does not guarantee cost savings that can be used for the maintenance of social goals. They also show the utility may have to finance social goals from additional profits that are earned in the distribution market; that is, cost reductions in the generation market, alone, are not sufficient to ensure that the utility-owned distribution company can contribute to the maintenance of social goals. 


\section{REGULATORY ACTIONS TO SUPPORT THE MAINTENANCE OF SOCIAL GOALS}

The preceding section has described how ad hoc reforms can enable the utility to earn additional profits to maintain social goals. The analysis prior to that described how the incentive regulation of the markets for unbundled transmission and distribution services could perform the same function. Additional regulatory actions designed to maintain social goals are discussed in this section. The first regulatory action is using the utility's unwillingness to lower prices in a monopolistic market to assist in the maintenance of social goals.

Monopolistic markets do not provide the utility with much inducement to lower its prices. Consequently, the utility-owned transmission and distribution companies are likely to increase prices rather than lower their costs to increase their profits under rate-of-return regulation. A portion of these additional profits can be diverted from investors to the maintenance of social goals. Therefore, it appears that the maintenance of social goals is possible under rate-of-return regulation after industry reform when regulatory authorities are prepared to let the utility-owned transmission and distribution companies exploit their market dominance in the their respective markets. Simply put, regulatory authorities have to be prepared to allow these companies to earn supranormal profits through price increases to ensure that the utility will continue to maintain social goals. ${ }^{51}$ The following analysis develops some additional ways for regulatory authorities to create profit opportunities for the utility.

It is not enough under rate-of-return regulation for regulatory authorities to ensure cost reductions at the expense of profitability because investors are as much

\footnotetext{
51 Although significant cost reductions by utility-owned generation companies are another element of a successful reform of the electricity industry, they may or may not be converted into profits. Competitive conditions in the generation market may prevent the utility-owned generation companies from converting their cost reductions into the supranormal profits that are used to support the maintenance of social goals.
} 
entitled to an opportunity to earn a fair rate of return on their investment as members of society are entitled to a clean environment. Fortunately, regulatory authorities can pursue different courses of action to achieve sufficient profitability by the utility-owned transmission and distribution companies.

One option is to require the utility-owned generation companies to contribute to the utility's recovery of its stranded costs. When these companies are forced to contribute to the recovery of stranded costs, the utility-owned transmission company has an incentive to lower its costs and increase its profitability. The latter, as an agent of the utility, wants to increase its profitability to protect the utility's investors from losses that utility-owned companies might experience in the generation market. In addition, it wants to lower its costs to hold down the transmission component of the prices of retail services sold by utility-owned distribution companies. This tactic ensures the good will of regulatory authorities and consumer groups.

Another option is for regulatory authorities to choose the least expensive way to protect consumers and others from anticompetitive behavior by the utility. Although not always a clear winner, the usual choice in this regard is nonstructural safeguards over structural separation. Even though the structural separation of the utility's generation, transmission, and distribution companies makes it easier for the regulatory authorities to uncover anticompetitive behavior, structural separation, in terms of out-of-pocket costs, always is a more expensive way to prevent anticompetitive behavior. However, the downside of nonstructural safeguards is the information maze that is created by cost allocations and restrictions on the flow of information within the utility.

The final option is for regulatory authorities to decide against the complete deregulation of the generation market. Complete deregulation leaves generation companies free to maximize their profits. Cost reductions by these companies, in this setting, will flow through to stockholders in the form of profits or to end users in the form of lower prices to ward off competitors. Either activity is made more 
difficult for the utility-owned generation companies when they voluntarily include an allowance to maintain social goals in their prices. Consequently, it is not likely that deregulated generation companies will act to maintain social goals.

As an alternative to the complete deregulation of the generation market, the regulatory authorities can retain jurisdiction over all generation companies for the limited purpose of ensuring their participation in the post-reform maintenance of social goals. ${ }^{52}$ For example, this limited jurisdiction can be used to create a Social Goal Support Fund that is financed through mandatory lump-sum fees collected from all generation companies. ${ }^{53}$ Although this fund may increase the cost of generation services, it does not remove the incentives that competition creates for the generation companies to reduce their operations, maintenance, administration, and management costs. To see why, consider a situation where generation companies have to pay a lump-sum fee of $\$ 100$ to support the maintenance of social goals, regardless of their respective levels of profitability. Suppose that these generation companies, on average, have profits of $\$ 500$ before they pay the fee. Obviously, the fee reduces average profits to $\$ 400$ per generation company. Now, suppose that these generation companies, on average, can cut their costs by $\$ 100$. Assume that the average profitability per generation company, before the assessment of the fee, increases to $\$ 575$ as a result of these cost reductions. In this instance, the average profitability of these generation companies, after the lump-sum fee, is $\$ 475$. The new average profitability captures all of the cost reductions for the stockholders. Essentially then, generation companies cut their own throats by not acting on incentives to cut their costs when they are assessed

${ }^{52}$ Although this level of regulatory oversight is slight, it may deter some firms from entering the generation sector of the industry. However, the deterred firms presumably would have high production costs.

${ }^{53}$ Another option available to regulatory authorities is to establish a fund that is financed through lump-sum fees collected from all generation, transmission, and distribution companies. 
a lump-sum fee. In effect, this fee has the character of a profits tax, which is a tax that does not alter pretax, profit-maximizing, competitive prices and outputs. ${ }^{54}$

As demonstrated, ways do exist for regulatory authorities to induce the utility to maintain social goals. However, some of these ways may not be feasible for regulatory authorities with particular desires in the area of bringing the benefits of competition to the generation market. Consider the following four social goals that might be embraced by any regulatory authority. Suppose that the regulatory authority wants to (1) set low prices for unbundled transmission and distribution services, (2) ensure the protection of the environment, (3) achieve economic development for its jurisdiction, and (4) have safe and reliable electricity. Assume the regulatory authority is serious about bringing the benefits of competition to the generation market.

This regulatory authority may be thought of as being committed to competition in the generation market. It is obvious that there will be more competitive generation companies when the prices for transmission-access services are low. Therefore, this regulatory authority would place low-priced unbundled regulation in the first position of its priority ranking. ${ }^{55}$ Low prices for transmissionaccess services are consistent with economic development because they imply low prices for retail services. Hence, economic development occupies the second rank. Low prices for transmission-access services imply more new generation companies, which, in turn, suggests a concern about the environment because new generation companies tend to be "cleaner" than old generation companies. Therefore, the

54 James M. Henderson and Richard E. Quandt, Microeconomic Theory: A Mathematical Approach (New York: McGraw-Hill Book Company, 1971), 219.

55 Priority rankings over social goals could be dominated by regulatory authorities, as is the case in fully regulated markets. Priority rankings could be totally within the control of the utility, as is the case in a completely deregulated market. Or, they may be the results of joint efforts of the utility and regulatory authorities to reconcile their differences, as is the case in a partially regulated market. Priority rankings, dominated by regulatory authorities, are examined in the remainder of this section. 
number three position is occupied by environmental protection. However, low prices for transmission-access services can affect the safeness and reliability of electricity when the utility shaves here and there with respect to the maintenance of facilities that connect the generation companies to the transmission company. This possibility puts safe and reliable electricity service in the fourth and final position.

The first ranking does not bode well for the maintenance of the last two social goals. A commitment to bring the benefits of competition to the generation market, because it induces the regulatory authority to set low prices for unbundled transmission-access services, will lead this regulatory authority to decide against allowing the utility to exploit its market dominance in the transmission market. This decision, if made, implies that fewer profits are available from the sale of transmission-access services for the maintenance of social goals with lower priorities. Therefore, a strong commitment to competition in the generation market by the regulatory authority reduces the utility's potential to maintain safe and reliable electricity and environmental protection, despite the fact that the transmission company is market dominant.

Although possible, the preceding ranking may not be feasible given the legal environment applicable to the electric power industry. At present, the regulatory authority has a legal obligation to ensure that consumers are provided with adequate, safe, and reliable electric services. In fact, this obligation tends to define the long-standing bargain between the utility and the regulatory authority, which makes it difficult for the regulatory authority to be as serious about bringing the benefits of competition to the generation market.

\section{CONCLUDING REMARKS}

The utility will find it very difficult to cope in the post-reform electric power industry, if it does not reduce its generation and transmission costs. Eventually, 
the utility's generation companies must earn competitive rates of return to satisfy their investors. Cost cutting in generation seems to be absolutely essential if this outcome is to be achieved. Regulatory authorities always want safe and reliable electricity service, but they also want low prices for unbundled transmission and distribution services. Low prices for these unbundled services means that the utility has to cut its transmission costs.

The utility's post-reform, coping task is made even more difficult when it has to maintain social goals. The maintenance of social goals is a drain on the utility's profitability. Although the utility may be able to earn an overall rate of return that is just high enough to satisfy its investors when it does not have to contribute to the maintenance of social goals, the utility would not be able to satisfy its investors when it has to maintain social goals. If nothing else changed the utility's earned rate of return and the utility was obligated to maintain social goals, then the utility would not earn enough to satisfy its investors. Instead, it would earn a rate of return that is below the competitive rate of return available to its investors. Therefore, to maintain social goals in a post-reform environment, the utility has to cut its costs and increase its profits to levels that imply a normal rate of return from generation and supranormal rates of return from the sale of unbundled regulated services.

The post-reform utility faces a competitive generation market, the substitution of unbundled services for bundled services, the sale of unbundled monopolistic services to competitors, the recovery of stranded costs, and the responsibility for the maintenance of social goals. These new circumstances cause the utility to be subject to a higher, overall level of risk. The higher risk level, in turn, means that the utility's post-reform profitability has to be greater than its prereform profitability. Consequently, the utility must extract more profits from somewhere. The somewhere is the markets for unbundled regulated services whether or not the utility is earning the competitive rate of return in the market for unbundled generation services. Therefore, the extraction of supranormal profits 
from regulated markets for unbundled services is the necessary and sufficient condition for the utility's maintenance of social goals after industry reform. If, for some reason, the utility cannot earn supranormal profits in these markets, then money will not be left over to maintain social goals after the competitive earnings are reinvested in the utility or distributed to its stockholders. Only in this way can the utility have an opportunity to maintain social goals and satisfy its investors.

Permissive language is used to describe the utility's capability to maintain social goals and satisfy its investors for the following reasons. First, a reasonable assertion is that the utility has dedicated a considerable amount of effort to lowering its production and administrative costs. If the utility is not allowed to keep a percentage of these cost savings in the form of additional profits for its investors, then it has little to no incentive to continue its efforts in this area. Second, investors expect higher rates of return from a competitive market as compared to a regulated market. Consequently, some of the additional profits due to cost cutting have to be used to increase the utility's earned rate of return in the generation market. Therefore, it might be the case that the additional profits available to the utility from the markets for unbundled regulated services are not sufficiently large enough to finance a higher overall rate of return and simultaneously continue the current maintenance of social goals.

As a result of industry reform, it is expected that the regulated electric utility will find it difficult to maintain support for social goals that increase its costs. A competitive generation market eliminates generation services as the source of a subsidy for social goals. A public policy endorsing competition in the generation market puts limits on the prices that can be charged for transmission-access services. Consequently, the practice of supporting social goals by shifting costs to bottleneck services may be in jeopardy of falling into disfavor within regulatory circles.

The two rankings of social goals discussed in the preceding section have different things to say about shifting costs to transmission-access services for the 
purpose of maintaining social goals. The endorsement of competition found in the first ranking implies that regulatory authorities will not readily shift the costs of social goals to transmission-access services, while the backing of safe and reliable service in the second ranking implies that these costs will find their way to transmission-access services.

In any event, six support mechanisms have been discussed that have the potential to continue the maintenance of social goals by the utility, as long as regulatory authorities are prepared to let the utility exploit its market power over transmission-access customers. In essence, the continued maintenance of social goals rests on the willingness of regulatory authorities to allow the utility to earn supranormal profits in monopolistic transmission and distribution markets. As mentioned, none of these mechanisms is perfect. 